This item was submitted to Loughborough's Research Repository by the author.

Items in Figshare are protected by copyright, with all rights reserved, unless otherwise indicated.

\title{
Polyaniline coated sulfonated TiO2 nanoparticles for effective application in proton conductive polymer membrane fuel cell
}

PLEASE CITE THE PUBLISHED VERSION

https://doi.org/10.1016/j.eurpolymj.2018.10.036

PUBLISHER

(C) Elsevier

VERSION

AM (Accepted Manuscript)

\section{PUBLISHER STATEMENT}

This paper was accepted for publication in the journal European Polymer Journal and the definitive published version is available at https://doi.org/10.1016/j.eurpolymj.2018.10.036.

\section{LICENCE}

CC BY-NC-ND 4.0

\section{REPOSITORY RECORD}

Elakkiya, S., G. Arthanareeswaran, A.F. Ismail, Diganta Das, and R. Suganya. 2018. "Polyaniline Coated Sulfonated Tio2 Nanoparticles for Effective Application in Proton Conductive Polymer Membrane Fuel Cell”. figshare. https://hdl.handle.net/2134/36241. 
1 Polyaniline coated sulfonated $\mathrm{TiO}_{2}$ nanoparticles for effective application in proton

2 conductive polymer membrane fuel cell

3 S. Elakkiya ${ }^{a}$, G. Arthanareeswaran ${ }^{a^{*}}$, A. F. Ismail ${ }^{b}$, Diganta B Das ${ }^{c}$, R.Suganya ${ }^{a}$

$4 \quad{ }^{a}$ Membrane Research Laboratory, Department of Chemical Engineering, National Institute of

5 Technology, Tiruchirappalli-620015, India

$6 \quad{ }^{b}$ Advanced Membrane Technology Research Centre (AMTEC), Universiti Teknologi Malaysia,

781310 Skudai, Johor, Malaysia

$8 \quad{ }^{c}$ Department of Chemical Engineering, Loughborough University, Loughborough LE11 3TU,

$9 U K$

10

11

12

13

14

15

16

17

18

19

20

21

$22{ }^{*}$ Corresponding author.

23 E-mail address: arthanaree10@yahoo.com (G. Arthanareeswaran).

24 Tel: +91431-2503118; Fax: +91431-2500133. 


\section{ABSTRACT}

26 The sulfonated polyethersulfone (SPES) with modified $\mathrm{TiO}_{2}$ proton exchange membrane

27 performance for the fuel cell application was reported. $\mathrm{TiO}_{2}$ nanoparticles investigated for the

28 fuel cell performance were modified by sulfonation and surface coated using polyaniline (PANI).

29 Fabricated membranes were analyzed in terms of water uptake, swelling ratio, methanol uptake, 30 ion exchange capacity, chemical stability and thermal properties. Surface and structural 31 properties of the membranes were characterized by Field Emission Scanning electron 32 microscope (FESEM). To understand the interaction between polymer and nanoparticle, Fourier 33 transform infrared (FTIR) and X-ray diffraction (XRD) characterization for the membranes were 34 performed. Highest proton conductivity is $2.30 \times 10^{-4} \mathrm{~S} / \mathrm{cm}$ with $\mathrm{SPES} / \mathrm{STiO}_{2}-\mathrm{PANI}(0.5 \%)$ 35 composite membrane. The presence of modified $\mathrm{TiO}_{2}$ with amine group of PANI and sulfonic 36 acid group were the main factors for the highest conductivity value. The composite membrane 37 with modified $\mathrm{TiO}_{2}$ shows excellent chemical stability and thermal properties. Thus, the composite membrane incorporated with $\mathrm{STiO}_{2}-\mathrm{PANI}$ is a promising proton conducting material 39 for fuel cell application.

Keywords: Sulfonated polyethersulfone; Surface modified $\mathrm{TiO}_{2}$; Emeraldine part of PANI;

41 Proton exchange membrane; Conductivity. 


\section{Introduction}

48 The fuel cell is a device which converts fuel into electricity and water through electrochemical reactions. High efficiency and eco-friendly technology with low emission of greenhouse gases

50 invade fuel cell to be a promising alternative clean energy resource [1, 2]. Proton exchange

51 membrane fuel cell (PEMFC) utilizes methanol or hydrogen for an automotive application as a 52 clean energy source [3]. The efficiency of the fuel cell system mainly depends on the 53 performance of the Proton exchange membrane (PEM) [4]. An ideal PEM should possess 54 excellent conductivity at an affordable price [5]. For the past few years, perfluorosulfonate 55 polymer Nafion was used as PEM in fuel cell system for its excellent proton conductivity [6, 7]. 56 Even though it exhibits this quality, high expenditure on the material, high fuel crossover, low 57 proton conductivity at high temperature and poor mechanical strength under hydrated condition 58 are the negative aspects of Nafion [8]. These challenges hinder the commercialization of the fuel 59 cell to a larger extent and thus it provokes the need for synthesis of alternative membrane material. The alternative membrane material should possess low fuel crossover, high

61 performance and high conductivity at low cost than Nafion [9].

62 In fuel cell technology, two types of materials have been used as PEM. The first is the usage of 63 organic polymer material alone which exhibits excellent chemical and thermal stability at low 64 cost [10]. The aromatic polymers used as an alternative membrane material are polyimide, 65 polybenzimidazole, poly(ether ether ketone), polysulfones, polyetherketones and 66 polyethersulfone [11]. These materials were used as PEM after sulfonation method. The second 67 kind is the use of an organic and inorganic material as components to synthesis the polymer 68 composite membrane which exhibits the synergistic properties of both the materials. $\mathrm{SiO}_{2}, \mathrm{TiO}_{2}$, 
$\mathrm{ZrO}_{2}, \mathrm{Al}_{2} \mathrm{O}_{3}, \mathrm{MMT}$, etc were used as an inorganic material for the preparation of composite

70 membranes [12].

71 Researchers have shown more attention towards thermoplastic polyethersulfone (PES) polymer

72 which has repeated phenyl and sulfone groups. PES exhibits excellent chemical, thermal and

73 mechanical properties [13]. Even though PES has unique physical properties, low proton

74 conductivity of this polymer drags the application in PEMFC. Sulfonation of PES is one of the

75 methods to make it suitable for fuel cell application $[14,15]$. The unique properties, easy and low

76 cost of synthesis have attracted the hydrocarbon-based sulfonated PES as a promising material in

77 PEMFC [16]. Recently, the properties of SPES membrane have been improved by impregnating

78 nanoparticle within the polymeric chain [17].

79 Pure conductivity polymers are chemically and mechanically unstable. For this reason, titanium 80 dioxide $\left(\mathrm{TiO}_{2}\right)$ and conducting polymer (PANI) are hybridized. Hygroscopic nature, high surface

81 area, photocatalytic and photoelectric conversion of $\mathrm{TiO}_{2}$ nanoparticle have attracted the 82 scientists to use it in various fields [18]. Sulfonation of $\mathrm{TiO}_{2}$ would increase the hydrophilic

83 nature of $\mathrm{TiO}_{2}$ and improves the ability to absorb more water molecules which might provide the 84 path for transport of protons [19].

85 Some interesting semiconducting polymers are phenylenediamines, alkoxyaniline, halogenated 86 anilines, aminophenols, aminobenzensulfonic acid, aminopyrene, dipheny-lamines, 1-amino-287 pyrridine, $\mathrm{N}$-alkylaniline, $\mathrm{N}, \mathrm{N}$-dimethylaniline and $\mathrm{N}$-phenylaniline [20]. Polyaniline (PANI) is 88 the polymeric product of aniline prepared under acidic condition. The conductive nature, easy of 89 synthesis, low cost for synthesis and environmental stability attracts PANI to be an effective 90 material for fuel cell application [21-24]. Among conducting polymers, PANI is the cheapest 91 material exhibits good conductivity [25]. Many researchers have studied the synthesis and 
92 characterization of $\mathrm{TiO}_{2}-\mathrm{PANI}$ composite membrane for various applications [26-29]. There is

93 no proper research work on synthesis and characterization of $\mathrm{STiO}_{2}-\mathrm{PANI}$ composite membrane

94 for fuel cell application.

95 In this work, the sulfonated polyethersulfone (SPES) was used as organic polymer phase. The 96 inorganic material ( $\mathrm{STiO}_{2}$ and $\mathrm{STiO}_{2}-\mathrm{PANI}$ nanocomposite) were synthesized and characterized

97 by FTIR and XRD. The composite membranes were prepared by incorporating the inorganic 98 materials within the polymeric phase individually at 0.5 and $1 \%$ loading rate.

99 2. Experimental

100

\subsection{Materials}

101

Polyethersulfone (PES) was purchased from RADEL A-300, Amoco Chemicals (Atlanta,

102 GA). Aniline and ammonium persulfate (APS) were procured from Finar Limited (India). Merck

103 (India) have provided sodium chloride $(\mathrm{NaCl})$, sodium hydroxide $(\mathrm{NaOH})$, phenolphthalein $1 \%$,

104 N-methyl-2-pyrrolidone (NMP) and hydrogen peroxide $\left(\mathrm{H}_{2} \mathrm{O}_{2}\right) \quad 30 \%$. Ammonium ferrous

105 sulphate was purchased from Loba Chemie Pvt. Ltd., India. Sulfuric acid $\left(\mathrm{H}_{2} \mathrm{SO}_{4}\right) 98 \%$ was

106 supplied by Thermo Fisher Scientific (India). Hydrochloric acid ( $\mathrm{HCl}$ ) 35\% was obtained from

107 Merck life science private limited, India. $\mathrm{TiO}_{2}$ nanoparticle was supplied by Sigma Aldrich.

108 2.2. Preparation of $\mathrm{STiO}_{2}$

109 The methodology followed for the preparation of $\mathrm{STiO}_{2}$ was reported in Zhimou et al.

110 [19]. $1 \mathrm{~g}$ of $\mathrm{TiO}_{2}$ nanoparticle was dispersed in $15 \mathrm{ml}$ of $0.5 \mathrm{M} \mathrm{H}_{2} \mathrm{SO}_{4}$ at room temperature. After

$1118 \mathrm{~h}$ of continuous stirring for sulfonation process, the solution was filtered, rinsed by deionized

112 water and dried at $90{ }^{\circ} \mathrm{C}$. The obtained powder was calcined at $500{ }^{\circ} \mathrm{C}$ for $3 \mathrm{~h}$ to obtain 113 sulfonated $\mathrm{TiO}_{2}\left(\mathrm{STiO}_{2}\right)$.

114 2.3. Preparation of $\mathrm{STiO}_{2}-\mathrm{PANI}$ nanocomposite 

reported in Xingwei et al. [28]. $1 \mathrm{ml}$ of aniline was added to $80 \mathrm{ml}$ of $2 \mathrm{M} \mathrm{HCl}$ solution

117 containing $1 \mathrm{~g}$ of $\mathrm{STiO}_{2}$ nanoparticle. After $10 \mathrm{~h}$ of continuous stirring, few drops of $5 \% \mathrm{FeSO}_{4}$

118 solution was added. Ammonium persulfate (APS) solution was prepared by dissolving $1 \mathrm{~g}$ of 119 Ammonium persulfate in $20 \mathrm{ml}$ of distilled water. APS solution was added in drop wise under 120 continuous stirring. The solution was allowed to polymerize at room temperature for $5 \mathrm{~h}$. The 121 polymerized solution was filtered, washed by $2 \mathrm{M} \mathrm{HCl}$ and deionized water for several times. 122 After drying in an oven at $60{ }^{\circ} \mathrm{C}$, green powder of $\mathrm{STiO}_{2}-\mathrm{PANI}$ nanocomposite was obtained. 123 The schematic representation of polyaniline coated sulfonated $\mathrm{TiO}_{2}$ is shown in Fig. 1.

124 Three interactions such as hydrogen bonding, coordinate bonding, electrostatic interactions and 125 sorption interaction are there at the $\mathrm{STiO}_{2}-\mathrm{PANI}$ interfaces. Hydrogen bonding may be formed 126 between aniline $\mathrm{NH}_{2}$ group and hydroxide group of the $\mathrm{STiO}_{2}$. Coordinate bonding might be 127 formed between the $\mathrm{NH}_{2}$ group of PANI and Ti atom of $\mathrm{STiO}_{2}$. Aniline monomers react with $128 \mathrm{HCl}$ to form anilinium chloride and there is an electrostatic interaction between the surface of $129 \mathrm{STiO}_{2}$ nanoparticles and anilinium chloride. APS was used as an oxidizing agent whom oxidizes 130 and polymerize aniline. While polymerization the molecular weight of the polymer increases and 131 their solubility in water gets decreased. As a result of this, the polymer gets deposited, adsorbed 132 and coated over the surface of $\mathrm{STiO}_{2}$ nanoparticles to form $\mathrm{STiO}_{2}-\mathrm{PANI}$ nanocomposite [18].

\subsection{Preparation and characterization of SPES}

$200 \mathrm{ml}$ of concentrated sulfuric acid is used to dissolve $20 \mathrm{~g}$ of PES polymer and stirred 135 vigorously until the solution becomes homogeneous. After $15 \mathrm{~h}$ of reaction time, the solution was poured into the ice cold water bath under continuous agitation to cease the sulfonation reaction. The SPES was filtered and washed with deionized water for several times until the $\mathrm{pH}$ 
138 becomes neutral $(\mathrm{pH}=7)$. Further, sulfonated polyethersulfone (SPES) was dried at $80{ }^{\circ} \mathrm{C}$ for

139 overnight. The presence of sulfonation group within the sulfonated polymer (SPES) backbone

140 was determined by ${ }^{1} \mathrm{H}-\mathrm{NMR}$ spectroscopy (Bruker Instrument, Germany).

$141 \quad$ 2.5. Preparation of polymer membranes

142 The polymer composite membranes were fabricated by phase inversion technique using

$143 \mathrm{~N}$-methyl-2-pyrrolidone (NMP) as a solvent. The synthesized $\mathrm{STiO}_{2}$ and $\mathrm{STiO}_{2}-\mathrm{PANI}$

144 nanocomposite were dissolved individually in NMP solvent at the loading rate of $0.5 \%$ and $1 \%$.

145 The compositions of the fabricated membranes were listed in Table 1. To the casting solutions,

146 SPES was added and stirred at $50^{\circ} \mathrm{C}$. After getting homogeneous mixture, the casting solutions

147 were kept aside for the removal of dissolved air bubbles and the solutions were casted onto a 148 glass plate using casting knife. For the removal of trapped solvent within the membrane, the 149 glass plates were dried for $12 \mathrm{~h}$ at $70{ }^{\circ} \mathrm{C}$. The membranes were detached from the glass and 150 stored for further study.

$151 \quad$ 2.6. Characterizations

152 FTIR and XRD analysis were performed for the prepared $\mathrm{STiO}_{2}$ and $\mathrm{STiO}_{2}-\mathrm{PANI}$ 153 nanocomposite. FESEM is useful to study the morphology and distribution of nanoparticle 154 within the polymer composite membrane. The gold sputter coated membrane was used for 155 FESEM analysis (Carl Zeiss, UK). To study the functional group, FTIR for the membrane was 156 recorded using Perkin Elmer/Spectrum 2, USA. XRD pattern for the membrane was analyzed 157 from $5^{\circ}$ to $90^{\circ}$ at $2 \theta$ angle using PANalytical $\mathrm{X}^{\prime}$ Pert Pro $(\mathrm{Cu}-\mathrm{K} \alpha$ radiation). 
The dried membrane weight was noted and soaked in deionized water at room temperature for overnight. The wet membrane was wiped with tissue paper and the wet weight

161 was noted. Water content was measured using the following equation.

$$
\text { Water Uptake }(\%)=\frac{(W-D)}{D} \times 100
$$

162 where $\mathrm{W}$ is the wet mass of the membrane and $\mathrm{D}$ is the dry mass of the membrane respectively.

163

164

165

166

167 the equation below.

$$
\text { Methanol Uptake }(\%)=\frac{(\text { Wet weight }- \text { Dry weight })}{\text { Dry weight }} \times 100
$$

\subsection{Swelling ratio}

The geometrical area of the membrane under hydrated (water) and dried conditions were recorded. The swelling ratio at room temperature was calculated as

$$
\text { Swelling ratio }(\%)=\frac{(\text { Wet membrane Area }- \text { Dry membrane Area })}{\text { Dry membrane Area }} \times 100
$$

\section{2.10. Ion Exchange Capacity (IEC)}

172 The dry membrane was soaked in $1 \mathrm{M} \mathrm{NaCl}$ for $24 \mathrm{~h}$ and it swaps the $\mathrm{H}^{+}$ions in the 173 membrane to $\mathrm{Na}^{+}$ions. The solution was neutralized with $0.012 \mathrm{M}$ of $\mathrm{NaOH}$ and phenolphthalein 174 was used as an indicator. From the titrated value, the IEC was measured by the given equation.

$$
\text { Ion exchange capacity }\left(\frac{\mathrm{meq}}{\mathrm{g}}\right)=\frac{\text { Volume } \times \text { Normality }}{\mathrm{D}}
$$

175 where $\mathrm{D}$ is the dry mass of the membrane $(\mathrm{g})$. 


\subsection{Chemical stability}

Fenton test is used to determine the chemical or oxidative stability of the membrane and it was determined by soaking the dry membrane in $3 \%$ of $\mathrm{H}_{2} \mathrm{O}_{2}$ aqueous solution at $68{ }^{\circ} \mathrm{C}$. Under continuous stirring $4 \mathrm{ppm}$ of ammonium ferrous sulphate was added. After fixed intervals of time, the membrane was removed from the solution and rinsed with water. The residual weight of the membrane was determined.

\subsection{Differential scanning calorimetry (DSC)}

Thermal property of the membrane was analyzed by Differential scanning calorimetry (DSC 6000-Perklin Elmer). The thermogram of the membrane was recorded under a nitrogen atmosphere between $20{ }^{\circ} \mathrm{C}$ and $350{ }^{\circ} \mathrm{C}$ which was scanned at a heating rate of $10{ }^{\circ} \mathrm{C} \mathrm{min}{ }^{-1}$.

\subsection{Proton conductivity}

The resistance of the membrane was recorded over the frequency range between $1 \mathrm{MHz}$ and $50 \mathrm{~Hz}$ with the amplitude of $10 \mathrm{mV}$ using potentiostat (Bio-logic VMP3, France). Prior to analysis, membrane was soaked in deionized water for overnight. The conductivity measurement cell with stainless steel electrodes would hold the membrane. The conductivity of the membrane was calculated by the equation below.

$$
\text { Proton Conductivity }(\mathrm{S} / \mathrm{cm})=\frac{\mathrm{d}}{\mathrm{R} \times \mathrm{S}}
$$

where $\mathrm{d}$ is the thickness of the membrane, $\mathrm{R}$ is the resistance and $\mathrm{S}$ is the surface area of the electrode respectively.

\section{Results and discussion}

\subsection{Confirmation of sulfonation using NMR spectroscopy}

The structure of PES and SPES were characterized by ${ }^{1} \mathrm{H}-\mathrm{NMR}$ spectroscopy and shown in Fig. 2. The spectrum for PES shown peaks at 7.3 and 8.0 were corresponds to the phenyl group 
198 present in the polymeric chain. For SPES, the down-field shift from 8.0 to $8.1 \mathrm{ppm}$ of the

199 hydrogen $(\mathrm{H})$ located in the ortho position at the aromatic ring confirms the presence of sulfonic 200 acid groups within the polymeric chain [30]. The appearance of new peaks in the SPES spectrum 201 also revealed that sulfonation was occurred in the PES polymer [31]. The introduction of 202 sulfonic acid groups could have a significant effect on the membrane properties such as IEC and 203 proton conductivity [32].

\subsection{Confirmation of functional group in nanoparticles and membranes using FTIR}

The functional group of modified $\mathrm{TiO}_{2}$ nanoparticle was analyzed by FTIR and the 206 spectra are shown in Fig. 3. For $\mathrm{STiO}_{2}$, the spectrum was wide, broad and there is no significant peak. Since during the synthesis of $\mathrm{STiO}_{2}$, the nanoparticle was calcined at high temperature $\left(500{ }^{\circ} \mathrm{C}\right)$ reported by Zhimou et al. [19] which might reduces the peak intensity. However, the XRD pattern for $\mathrm{STiO}_{2}$ nanoparticle shown peak at $2 \theta$ of $25.3^{\circ}$ which confirms the sulfonation of $\mathrm{TiO}_{2}$ nanoparticle which is in accordance with the XRD result of Zhimou et al. and it was

211 explained in section 3.3.Thus the spectra appeared to be broad. The spectra for $\mathrm{STiO}_{2}$ have

212 confirmed the sulfonation of $\mathrm{TiO}_{2}$ nanoparticle. For $\mathrm{STiO}_{2}-\mathrm{PANI}$ nanocomposite, an $\mathrm{N}-\mathrm{H}$ 213 stretching spectrum occurs at $3447 \mathrm{~cm}^{-1}$. At $1581 \mathrm{~cm}^{-1}$, the spectra corresponds to $\mathrm{C}=\mathrm{N}$ of 214 quinonoid ring and peak at $1481 \mathrm{~cm}^{-1}$ corresponds to $\mathrm{C}=\mathrm{C}$ benzenoid ring stretching. $\mathrm{C}-\mathrm{N}$ 215 stretching of benzenoid ring spectra occurs at $1290 \mathrm{~cm}^{-1}$. The characteristic band detected at $2161121 \mathrm{~cm}^{-1}$ corresponds to quinonoid unit of PANI [18]. The broad band at $503 \mathrm{~cm}^{-1}$ attributed to $217 \mathrm{Ti}-\mathrm{O}$. For $\mathrm{STiO}_{2}-\mathrm{PANI}$ nanocomposite, the spectra have confirmed that the presence of both $218 \mathrm{STiO}_{2}$ and conducting emeraldine part of PANI. When Compared to $\mathrm{STiO}_{2}$, new peaks were 219 appeared in $\mathrm{STiO}_{2}-\mathrm{PANI}$ nanocomposite which represents the strong interaction between PANI 220 and $\mathrm{STiO}_{2}[25]$. 
221 Fig. 4 shows the spectra of SPES composite membranes. All membranes exhibit spectra at 1235

$222 \mathrm{~cm}^{-1}$ are assigned to $\mathrm{C}-\mathrm{O}-\mathrm{C}$ stretching of PES. The stretching of sulfonate group for SPES and 223 composite membranes are revealed at $1088 \mathrm{~cm}^{-1}$ [33]. The peaks at $1,230 \mathrm{~cm}^{-1}$ and $1088 \mathrm{~cm}^{-1}$ 224 represents the asymmetric $\mathrm{O}=\mathrm{S}=\mathrm{O}$ and symmetric $\mathrm{O}=\mathrm{S}=\mathrm{O}$ stretching vibrations. These peaks in 225 SPES and composite membranes confirm the presence of sulfonic acid group [34].

226

227

228

229

230

231

232

233

234

235

236

237

238

239

240

241

242

\subsection{XRD analysis for synthesized nanoparticles and membranes}

XRD patterns for $\mathrm{STiO}_{2}$ and $\mathrm{STiO}_{2}-\mathrm{PANI}$ nanocomposite are shown in Fig. 5.For $\mathrm{STiO}_{2}$, the significant peak at $2 \theta=25.3^{\circ}$ shows the crystallographic nature and using Debye-Scherrer's equation, the crystallite size of $\mathrm{STiO}_{2}$ was found as $8.1 \mathrm{~nm}[19]$. The peaks at $2 \theta=27.4^{\circ}, 37.8^{\circ}$, $47.9^{\circ}, 54^{\circ}, 62.6^{\circ}$ and $68.9^{\circ}$ for $\mathrm{STiO}_{2}$ shows the characteristic peaks of crystalline $\mathrm{TiO}_{2}$. For $\mathrm{STiO}_{2}-\mathrm{PANI}$ nanocomposite, the highest peak appeared at $2 \theta$ of $20.3^{\circ}$ is for PANI. The interaction between PANI and $\mathrm{STiO}_{2}$ has decreased the crystalline nature. When the deposited

PANI was absorbed on the $\mathrm{STiO}_{2}$ surface, the interaction between PANI and $\mathrm{STiO}_{2}$ restrict the formation of the polymeric chain around $\mathrm{STiO}_{2}$ nanoparticle [25]. Thus, the crystalline nature of PANI is hindered and reduces the degree of crystallinity [28]. The XRD pattern of $\mathrm{STiO}_{2}-\mathrm{PANI}$ nanocomposite shows the characteristic peaks of both $\mathrm{STiO}_{2}$ and PANI [22]. The spectra also represent the ordered arrangement of PANI in the nanocomposite [29].

Fig. 6 shows the diffraction patterns of SPES composite membranes. For all the membranes, the broad band at $2 \theta$ of $10^{\circ}$ and $20^{\circ}$ represents the amorphous nature of base SPES polymer which is arisen from the hydrophilic sulfonic acid group [33]. The composite membranes exhibit peak at $2 \theta$ value of $18^{\circ}$ beside this value show weak peak.

\subsection{Surface morphology of membranes}


FESEM image of SPES composite membranes are shown in Fig. 7. The surface

244 morphology of the composite membranes represents the interaction between nanoparticles

$245\left(\mathrm{STiO}_{2}\right.$ and $\left.\mathrm{STiO}_{2}-\mathrm{PANI}\right)$ and polymer matrix. The membranes were appeared to be

246 homogeneous with nonporous structure. The nonporous structure of the membrane is formed by

247 the dry phase inversion technique. During fabrication, the slow movement of solvent from the

248 membrane creates non porous structure. The transport of proton through PEM is governed by

249 morphology of the membrane. The dense membrane is suitable for fuel cell application because

250 it retard the movement of substrate and promotes the movement of protons. In $\mathrm{SPES} / \mathrm{STiO}_{2}-$

251 PANI composite membrane, the added $\mathrm{STiO}_{2}-\mathrm{PANI}$ nanocomposite was tightly bound to the

252 polymer chain.

\section{3.5. Water uptake and swelling ratio}

254 Water uptake is a vital requirement for PEM because it aids the transfer of proton through 255 the membrane [35]. The water uptake for SPES composite membranes are given in Table 2. The 256 highest value is $7.18 \%$ with $\mathrm{STiO}_{2}-\mathrm{PANI}(1 \%)$ compared to all the membranes. Hygroscopic 257 nature of added $\mathrm{STiO}_{2}-\mathrm{PANI}$ and the bonding between $\mathrm{OH}$ group of $\mathrm{STiO}_{2}$ and water molecules 258 acts as a vehicle to accommodate water molecules. This facilitates the membrane to imbibe more 259 water molecules which helps to enhance proton conductivity [36]. The water uptake value 260 increased when the loading rate of $\mathrm{STiO}_{2}-\mathrm{PANI}$ has increased from 0.5 to $1 \%$. Since the 261 increased loading of $\mathrm{STiO}_{2}-\mathrm{PANI}$ increases the hydrophilic region of the membrane matrix. The 262 difference in the water uptake value is also due to the morphology of the membrane which has its 263 influence on the interconnections of ionic cluster responsible for water absorption [34]. 
264 The swelling ratio of the membranes was less than $1 \%$ for all the membranes and exhibits good 265 stability with negligible swelling. Since the mobility of the polymeric chain is hindered by the 266 added nanoparticle which decreases the swelling properties.

\section{3.6. Methanol uptake}

Table 3 shows the percentage of methanol uptake of SPES and composite membranes.

269 Methanol uptake (2M) was slightly greater than the water uptake for all the membranes except $270 \mathrm{SPES} / \mathrm{STiO}_{2}(0.5 \%)$ and $\mathrm{SPES} / \mathrm{STiO}_{2}-\mathrm{PANI}(0.5 \%)$ membranes. This result indicates that the $271 \mathrm{SPES} / \mathrm{STiO}_{2}(0.5 \%)$ and $\mathrm{SPES} / \mathrm{STiO}_{2}-\mathrm{PANI}(0.5 \%)$ membranes exhibits lesser attraction for the 272 methanol than the water. While the lack of interaction between the ionic moieties present in the 273 membrane matrix and methanol reduces the methanol uptake. In addition, the cross-linking 274 between the emeraldine part of PANI and sulfonic group in the membrane matrix might be the 275 reason for the observed behavior at low methanol concentration [21]. For pure methanol, the 276 methanol uptake of all the membranes were found to be highest than the $2 \mathrm{M}$ and $5 \mathrm{M}$ methanol 277 uptake. Since the sulfonation groups within the membrane matrix have greater attraction 278 towards methanol [2].

\section{3.7. Ion Exchange Capacity}

The IEC of SPES and composite membranes are listed in Table 2. The IEC value

281 decreases in the order of SPES/STiO $2-\mathrm{PANI}(0.5 \%)>\mathrm{SPES} / \mathrm{STiO}_{2}(1 \%)>\mathrm{SPES} / \mathrm{STiO}_{2}(0.5 \%)$

$282>$ SPES $>$ SPES/ $\mathrm{STiO}_{2}-\mathrm{PANI}(1 \%)$. The IEC value of SPES/ $\mathrm{STiO}_{2}-\mathrm{PANI}(0.5 \%)$ is highest

283 when compared with all the membranes. The result states that the presences of sulfonic acid 284 groups provide by added $\mathrm{STiO}_{2}-\mathrm{PANI}$ is responsible for ion exchange. The IEC value depends 285 on the presence of sulfonic group within the polymeric matrix and makes positive effects on 286 proton conductivity [33]. There was a negative impact on IEC when $\mathrm{STiO}_{2}-\mathrm{PANI}$ loading was 
287 increased from $0.5 \%$ to $1 \%$. This is because of the development of secondary amine groups, 288 neutralization or counteract of sulfonic groups, compact structure and the formation of hydrogen 289 bond with the sulfonated membrane matrix [21,37].

290

291

292

293

294

295

296

297

298

299

300

301

302

303

304

305

306

307

308

309

\subsection{Chemical stability}

Membrane stability in Fenton's reagent (oxidative environment) is an important factor to evaluate the PEM performance for fuel cell application. In PEMFC, the hydroxyl and hydro peroxy radicals generated are effective to attack membrane. These free radicals were generated during the decomposition of $\mathrm{H}_{2} \mathrm{O}_{2}$ catalyzed by ions and iron [38, 39]. The composite membranes were found to be stable in the Fenton's reagent for the fixed intervals of time.

\subsection{Glass transition temperature $\left(T_{g}\right)$}

The thermogram pattern of SPES composite membranes are shown in Fig. 8. Tg values were 234, 250, 246, 263 and $251{ }^{\circ} \mathrm{C}$ for SPES, SPES/STiO $2(0.5 \%), \mathrm{SPES} / \mathrm{STiO}_{2}(1 \%), \mathrm{SPES} /$ $\mathrm{STiO}_{2}-\mathrm{PANI}(0.5 \%)$ and $\mathrm{SPES} / \mathrm{STiO}_{2}-\mathrm{PANI}(1 \%)$ membranes respectively. In the composite membrane, the hydroxyl groups provide by added nanoparticles are interconnected by hydrogen bonding was responsible for high $\mathrm{T}_{\mathrm{g}}$. Additionally, the sulfonic acid group interaction also hinder the mobility of the polymeric chain and it shift the $\mathrm{T}_{\mathrm{g}}$ to higher value [40]. From the thermogram, $\mathrm{T}_{\mathrm{g}}$ was found to be greater than $250{ }^{\circ} \mathrm{C}$ which is higher than the normal operating temperature of PEMFC. Highest $\mathrm{T}_{\mathrm{g}}$ is desirable for application of PEM in fuel cell system that gives the assurance for good thermal and dimensional stability intended for working under fuel cell operating conditions [41].

\subsection{Proton conductivity}

Table 2 shows the proton conductivity of SPES and composite membranes. The highest value is $2.30 \times 10^{-4} \mathrm{~S} / \mathrm{cm}$ with $\mathrm{SPES} / \mathrm{STiO}_{2}-\mathrm{PANI}(0.5 \%)$ membrane. The high proton 
310 conductivity might be owing to the substantial affinity of hydrophilic region towards water. The

311 amine groups of PANI provide by added $\mathrm{STiO}_{2}-\mathrm{PANI}$ and the presence of sulfonic acid group

312 contributes to form hydrophilic region in the membrane. Since it is responsible to hold water

313 molecules for interconnecting the ionic domains within the polymer matrix and helps to transfer

314 the proton $[42,43]$. Additionally, the amine group of PANI ( $\mathrm{STiO}_{2}-\mathrm{PANI}$ nanocomposite) may

315 form cross linking with the $-\mathrm{SO}_{3} \mathrm{H}$ of SPES membrane matrix which hydrate the hydrophilic

316 groups. The water molecules assist in proton movement and thus contributed to conductivity by

317 water hopping mechanism [36]. But, on increasing the loading rate of $\mathrm{STiO}_{2}-\mathrm{PANI}$ from 0.5 to

$3181 \%$ has a negative impact on conductivity value owing to the reduction of IEC. Significant/high

319 proton conductivity is the vital factor required by the membrane to act as a proton exchanger.

320 Low proton conductivity expressed by other membranes was due to the segregation of ionic

321 domain within the polymeric structure.

322 4. Conclusions

323

Surface modified $\mathrm{TiO}_{2}\left(\mathrm{STiO}_{2}\right.$ and $\mathrm{STiO}_{2}-\mathrm{PANI}$ nanocomposite $)$ were synthesized and

324 characterized by FTIR and XRD. Sulfonation of PES was also carried out and studied by ${ }^{1} \mathrm{H}-$

325 NMR spectroscopy. The highest proton conductivity value is $2.30 \times 10^{-4} \mathrm{~S} / \mathrm{cm}$ exhibited by

$326 \mathrm{SPES} / \mathrm{STiO}_{2}-\mathrm{PANI}(0.5 \%)$ composite membrane. $\mathrm{STiO}_{2}-\mathrm{PANI}$ in the polymer matrix enhanced

327 ion exchange capacity due to presence of sulfonic acid group and amine group. The ionic

328 domains present within the membrane were interconnected by the movement of water which

329 influences the conductivity value. In addition to this, the SPES/STiO $2-\mathrm{PANI}(0.5 \%)$ composite

330 membrane also exhibit better fuel cell properties than the pristine SPES membrane. On

331 increasing the loading rate of $\mathrm{STiO}_{2}-\mathrm{PANI}$ nanocomposite from $0.5 \%$ to $1 \%$ have a negative

332 impact on proton conductivity value. Since the reduction of IEC lessen the proton transfer and 
333 thereby reduces proton conductivity. The effect of $\mathrm{STiO}_{2}-\mathrm{PANI}$ nanocomposite on the PEM was

334 found to be suitable with good conductivity property than the pristine SPES membrane and it 335 would be a promising conductive material for the preparation of composite membrane in the fuel

336 cell application.

337 Acknowledgments

338 The authors (SE, GA and DBD) are thankful to Royal Academy of Engineering, UK for Newton339 Bhabha Higher Education Initiative Fund (Grant Number: HEP151642). The research work was 340 financially supported by the above India-UK collaborative fund.

341 The authors acknowledge Dr.S. Vengatesan, CSIR-Central Electrochemical Research Institute, 342 Karaikudi for providing proton conductivity analysis.

\section{References}

344 [1] M.R. Molavian, A. Abdolmaleki, K.F. Tadavani, M. Zhiani, A new sulfonated poly(ether 345 sulfone) hybrid with low humidity dependence for high-temperature proton exchange membrane fuel cell applications, J. Appl. Polym. Sci. 134 (2017) 45342.

347 [2] R.L. Thankamony, M. Won, T.H. Kim, Terminally-crosslinked poly(ether sulfone) block 348 copolymer, as a highly selective and stable polymer electrolyte membrane for DMFC applications, Int. J. Hydrogen Energy 38 (2013) 5084-5091.

350 [3] H.L.Wu, C.C.M Ma, L.F. Liu, C.Y. Chen, S.J. Lee, Chiang CL, Preparation and 351 characterization of poly(ether sulfone)/sulfonated poly(ether ether ketone) blend membranes, Eur. Polym. J. 42 (2006) 1688-1695.

353 [4] S. Swier, V. Ramani, J.M. Fenton, H.R. Kunz, M.T. Shaw, R.A. Weiss, Polymer blends based on sulfonated poly(ether ketone ketone) and poly(ether sulfone) as proton exchange membranes for fuel cells, J.Membr. Sci. 256 (2005) 122-133. 
[5] V. Neburchilov, J. Martin, H. Wang, J. Zhang, A review of polymer electrolyte membranes for direct methanol fuel cells, J. Power Sources 169 (2007) 221-238.

[6] B. Hossein, J. Mehran, S. Parisa, B. Ahmad, A. Ali, Novel proton exchange membrane nanocomposites based on sulfonated tungsten trioxide for application in direct methanol fuel cells, Polymer 119 (2017) 253-262.

[7] N. Awang, A.F. Ismail, J. Jaafar, T. Matsuura, H. Junoh, M.H.D. Othman, M.A. Rahman, Functionalization of polymeric materials as a high performance membrane for direct methanol fuel cell: A review, React. Funct.Polym. 86 (2015) 248-258.

[8] S.S. Mohtar, A.F. Ismail, T. Matsuura, Preparation and characterization of SPEEK/MMTSTA composite membrane for DMFC application, J. Membr. Sci. 371 (2011) 10-19.

[9] H.J. Kim, N.N. Krishnan, S.Y. Lee, S.Y. Hwang, T.H. Lim, et al, Sulfonated poly(ether sulfone) for universal polymer electrolyte fuel cell operations, J.Power Sources 160 (2006) $353-358$.

[10] K.D. Kreur, Proton Conductivity: Materials and Applications, Chem. Mater 8 (1996) 610641.

[11] F. Lufrano, V. Baglio, P. Staiti, A.S. Arico, V. Antonucci, Polymer electrolytes based on sulfonated polysulfone for direct methanol fuel cells, J.Power Sources 179 (2008) 34-41.

[12] H. Ilbeygi, A.F. Ismail, A. Mayahi, M.M. Nasef, J. Jaafar, E. Jalalvandi, Transport properties and direct methanol fuel cell performance of sulfonated poly (ether ether ketone)/Cloisite/triaminopyrimidine nanocomposite polymer electrolyte membrane at moderate temperature, Sep Purif Technol 118 (2013) 567-575. 
377 [13] V. Sabatini, S. Checchia, H. Farina, M.A. Ortenzi, Homogeneous Synthesis and

378

Characterization of Sulfonated Polyarylethersulfones Having Low Degree of Sulfonation and Highly Hydrophilic Behavior, Macromol. Res. 24 (2016) 800-810.

[14] S. Neelakandan, P. Kanagaraj , A. Nagendran, D. Rana, T. Matsuura, A. Muthumeenal, Enhancing proton conduction of sulfonated poly (phenylene ether ether sulfone) membrane by charged surface modifying macromolecules for $\mathrm{H}_{2} / \mathrm{O}_{2}$ fuel cells, Renewable Energy 78 (2015) 306-313.

[15] F. Caruso, Nanoengineering of particle surfaces. Adv. Mater. 13 (2001) 11-22.

[16] C.K. Shin, G. Maier, G.G. Scherer, Acid functionalized poly(arylene ether)s for protonconducting membranes. J.Membr. Sci. 245 (2004) 163-173.

[17] S. Gahlot, P.P. Sharma, V. Kulshrestha, P.K. Jha, SGO/SPES-Based Highly Conducting Polymer Electrolyte Membranes for Fuel Cell Application, ACS Appl. Mater. Interfaces 6 (2014) 5595-5601.

[18] X. Li, D. Wang, Q. Luo, J. An, Y. Wang, G. Cheng, Surface modification of titanium dioxide nanoparticles by polyaniline via an in situ method, J. Chem. Technol. Biotechnol. 83 (2008) 1558-1564.

[19] Z. Wu, G. Suna, W. Jin, H. Hou, S. Wang, Q. Xin, Nafion ${ }^{\circledR}$ and nano-size $\mathrm{TiO}_{2}-\mathrm{SO}_{4}{ }^{2-}$ solid superacid composite membrane for direct methanol fuel cell, J.Membr. Sci. 313 (2008) 336-343.

[20] B. Salma, F. Shehna, A.S. Anwar-ul-Haq, H. Rudolf, Improved solubility, conductivity, thermal stability and corrosionprotection properties of poly(o-toluidine) synthesized via chemical polymerization, Synthetic Metals 197 (2014) 144-153. 
399 [21] R.K. Nagarale, G.S. Gohil, V.K. Shahi, Sulfonated poly(ether ether ketone)/polyaniline 400 composite proton-exchange membrane, J.Membr. Sci. 280 (2006) 389-396.

401 [22] S. Srivastava, S. Kumar, V.N. Singh, M. Singh, Y.K. Vijay, Synthesis and characterization 402

403

404 405

406

407

[25] H.S. Xia, Q. Wang, Ultrasonic irradiation: a novel approach to prepare conductive polyaniline/nanocrystalline titanium oxide composites, Chem, Mater, 14 (2002) 21582165.

[26] L.J. Zhang, M.X. Wan, Polyaniline/TiO 2 composite nanotubes, J. Phys. Chem. B 107 (2003) 6748-6753.

[27] S.X. Xiong, Q. Wang, H.S. Xia, Template synthesis of polyaniline $/ \mathrm{TiO}_{2}$ bilayer microtubes, Synth. Met. 146 (2004) 37-42.

[28] X. Li, W. Chen, C.B.J. He, N. Xu, G. Xue, Surface modification of $\mathrm{TiO}_{2}$ nanoparticles by polyaniline, Appl. Surf. Sci. 217 (2003) 16-22.

[29] S. Bhadra, D. Khastgir, N.K. Singha, J.H. Lee, Progress in preparation, processing and applications of polyaniline, Prog. Polym. Sci. 34 (2009) 783-810. 
421 [30] M. Tang, J.Xue, K.Yan, T. Xiang, S. Sun, C. Zhao, Heparin-like surface modification of

422

423

424

425

426

427

428

429

430

431

432

433

434

435

436

437

438

439

440

441

442 polyethersulfone membrane and its biocompatibility, Journal of Colloid and Interface Science 386 (2012) 428-440.

[31] L.Y. Thuyavan, N. Anantharaman, G. Arthanareeswaran, A.F. Ismail, R.V. Mangalaraja, Preparation and characterization of $\mathrm{TiO}_{2}$-sulfonated polymer embedded polyetherimide membranes for effective desalination application, Desalination 365 (2015) 355-364.

[32] M.M. Hasani-Sadrabadi, S.H. Emami, R. Ghaffarian, H. Moaddel, Nanocomposite membranes made from sulfonated poly (ether ether ketone) and montmorillonite clay for fuel cell applications, Energy Fuels 22 (2008) 2539-2542.

[33] A. Muthumeenal, S. Neelakandan, P. Kanagaraj, A. Nagendran, Synthesis and properties of novel proton exchange membranes based on sulfonated polyethersulfone and $\mathrm{N}$-phthaloyl chitosan blends for DMFC applications, Renewable Energy 86 (2016) 922-929.

[34] A. Muthumeenal, S. Neelakandan, D. Rana, T. Matsuura, P. Kanagaraj, A. Nagendran, Sulfonated Polyethersulfone (SPES)-Charged Surface Modifying Macromolecules (cSMMs) Blends as a Cation Selective Membrane for Fuel Cells, Fuel cells 14 (2014) 853861.

[35] K. Deepa, M. Kesava, R. Sureshkumar , K. Dinakaran ,G. Arthanareeswaran, Synthesis and electrochemical properties of blend membranes of polysulfone and poly (acrylic acidco-2-(2-(piperazin-1-yl) ethylamino)-2-hydroxyethyl methacrylate) for proton exchange membrane fuel cell, Int. J. Hydrogen Energy ( 201018 ) 1 -9.

[36] S. Elakkiya , G. Arthanareeswaran, K. Venkatesh, J. Kweon, Enhancement of fuel cell properties in polyethersulfone and sulfonated poly (ether ether ketone) membranes using 
metal oxide nanoparticles for proton exchange membrane fuel cell, Int. J. Hydrogen Energy ( 2018 ) 1-10.

445

446

447

448

449

450

451

452

453

454

455

456

457

458

459

460

461

462

463

464

465

[37] L. Xianfeng, C. Dongju, X. Dan, Z. Chengji, W. Zhe, L. Hui, N. Hui, SPEEKK/polyaniline (PANI) composite membranes for direct methanol fuel cell usages, J.Membr. Sci. 275 (2006) 134-140.

[38] L. Ghassemzadeha, K.D. Kreuera, J. Maiera, K. Müller, Evaluating chemical degradation of proton conducting perfluorosulfonic acid ionomers in a Fenton test by solid-state 19F NMR spectroscopy, J. Power Sources 196 (2011) 2490-2497.

[39] T. Sugawara, N. Kawashima, T.N. Murakami, Kinetic study of Nafion degradation by Fenton reaction, J. Power Sources 196 (2011) 2615-2620.

[40] S. Wen, C. Gong, Y.C. Shu, F.C. Tsai, J.T. Yeh, Sulfonated Poly(ether sulfone)/Phosphotungstic acid/attapulgite composite membranes for direct methanol fuel cells. J. Appl. Polym. Sci. 123 (2012) 646-656.

[41] A. Iulianelli, G. Clarizia, A. Gugliuzza, D. Ebrasu, A. Bevilacqua, F. Trotta, A. Basile, Sulfonation of PEEK-WC polymer via chloro-sulfonic acid for potential PEM fuel cell applications. Int. J. Hydrogen Energy 35 (2010) 12688-12695.

[42] M.M. Hasani-Sadrabadi, E. Dashtimoghadam, S.R. Ghaffarian, M.H. Hasani Sadrabadi, M. Heidari, H. Moaddel, Novel high-performance nanocomposite proton exchange membranes based on poly (ether sulfone), Renewable Energy 35 (2010) 226-231.

[43] T. Fua, Z. Cuib, S. Zhong, Y. Shid, C. Zhaoa, G. Zhanga, K. Shaoa, H. Naa, W. Xing, Sulfonated poly(ether ether ketone)/clay- $\mathrm{SO}_{3} \mathrm{H}$ hybrid proton exchange membranes for direct methanol fuel cells, J.Power Sources 185 (2008) 32-39. 
466 Table captions

467 Table 1

468 Composition of the fabricated membranes.

469 Table 2

470 Thickness, Water uptake, IEC and conductivity of the membranes.

$471 \quad$ Table 3

472 Methanol uptake of the polymer membranes.

473

474

475

476

477

478

479

480

481

482 


\section{Table 1}

484 Composition of the fabricated membranes.

\begin{tabular}{|c|c|c|c|}
\hline Membrane Name & Modified $\mathrm{TiO}_{2}(\mathrm{~g})$ & SPES (g) & Solvent (ml) \\
\hline SPES & - & 3.2708 & 15 \\
\hline 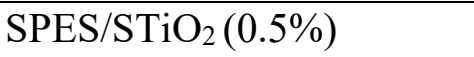 & 0.0164 & 3.2544 & 15 \\
\hline $\mathrm{SPES} / \mathrm{STiO}_{2}(1 \%)$ & 0.0327 & 3.2381 & 15 \\
\hline SPES/STiO $2-\mathrm{PANI}(0.5 \%)$ & 0.0164 & 3.2544 & 15 \\
\hline SPES/ $\mathrm{STiO}_{2}-\mathrm{PANI}(1 \%)$ & 0.0327 & 3.2381 & 15 \\
\hline
\end{tabular}

485

486

487

488

489

490

491

492

493

494

495 
497 Thickness, Water uptake, IEC and conductivity of the membranes.

\begin{tabular}{|c|c|c|c|c|}
\hline Membrane Name & Thickness (cm) & $\begin{array}{l}\text { Water uptake } \\
(\%)\end{array}$ & $\begin{array}{l}\text { IEC } \\
(\mathrm{meq} / \mathrm{g})\end{array}$ & $\begin{array}{l}\text { Proton } \\
\text { Conductivity } \\
(\mathrm{S} / \mathrm{cm})\end{array}$ \\
\hline SPES & 0.0061 & $3.47(0.59)$ & $0.67(0.04)$ & $2.32 \times 10^{-5}(0.28)$ \\
\hline 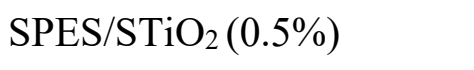 & 0.0058 & $3.70(0.26)$ & $0.69(0.03)$ & $2.81 \times 10^{-5}(0.22)$ \\
\hline $\mathrm{SPES} / \mathrm{STiO}_{2}(1 \%)$ & 0.0059 & $2.48(0.50)$ & $0.72(0.05)$ & $5.74 \times 10^{-5}(0.26)$ \\
\hline $\mathrm{SPES}_{\mathrm{STiO}}-\mathrm{PANI}(0.5 \%)$ & 0.0058 & $4.54(0.44)$ & $0.80(0.03)$ & $2.30 \times 10^{-4}(0.32)$ \\
\hline SPES/ $\mathrm{STiO}_{2}-\mathrm{PANI}(1 \%)$ & 0.0058 & $7.18(0.40)$ & $0.50(0.01)$ & $5.16 \times 10^{-5}(0.36)$ \\
\hline
\end{tabular}

(Values in parentheses are standard deviation).

499

500

501

502

503

504

505

506

507

508

509

510 


\section{Table 3}

512 Methanol uptake of the polymer membranes.

\begin{tabular}{|c|c|c|c|}
\hline & \multicolumn{3}{|c|}{ Methanol uptake $(\%)$} \\
\hline Membrane & 2 M Methanol & 5 M Methanol & Pure Methanol \\
\hline SPES & 5.26 & 4.17 & 13.83 \\
\hline 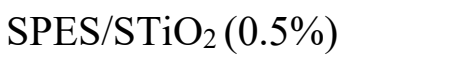 & 1.74 & 4.35 & 14.66 \\
\hline $\mathrm{SPES} / \mathrm{STiO}_{2}(1 \%)$ & 2.59 & 12.96 & 12.06 \\
\hline $\mathrm{SPES} / \mathrm{STiO}_{2}-\mathrm{PANI}(0.5 \%)$ & 3.34 & 5.40 & 16.39 \\
\hline SPES/ STiO $2-\mathrm{PANI}(1 \%)$ & 8.23 & 6.98 & 18.82 \\
\hline
\end{tabular}

513

514

515

516

517

518

519

520

521

522

523

524

525

526 


\section{Figure captions}

528 Fig. 1. Schematic representation of Polyaniline coated sulfonated $\mathrm{TiO}_{2}$ nanoparticles

529 Fig. 2. ${ }^{1} \mathrm{H}-\mathrm{NMR}$ spectra of PES and SPES.

530 Fig. 3. FTIR spectra of $\mathrm{TiO}_{2}, \mathrm{STiO}_{2}$ and $\mathrm{STiO}_{2}-\mathrm{PANI}$.

531 Fig. 4. FTIR spectra of pristine SPES and SPES composite membranes.

532 Fig. 5. XRD pattern of $\mathrm{STiO}_{2}$ and $\mathrm{STiO}_{2}-\mathrm{PANI}$.

533 Fig. 6. XRD pattern of pristine SPES and SPES composite membranes.

534 Fig. 7. FESEM images of the membranes (a) SPES, (b) SPES/STiO $2\left(0.5 \%\right.$ ), (c) SPES/ $\mathrm{STiO}_{2}$

535 (1\%), (d) SPES/ STiO $2-P A N I(0.5 \%)$ and (e) SPES/ $\mathrm{STiO}_{2}-\mathrm{PANI}(1 \%)$.

536 Fig. 8. DSC thermogram of pristine SPES and SPES composite membranes. 

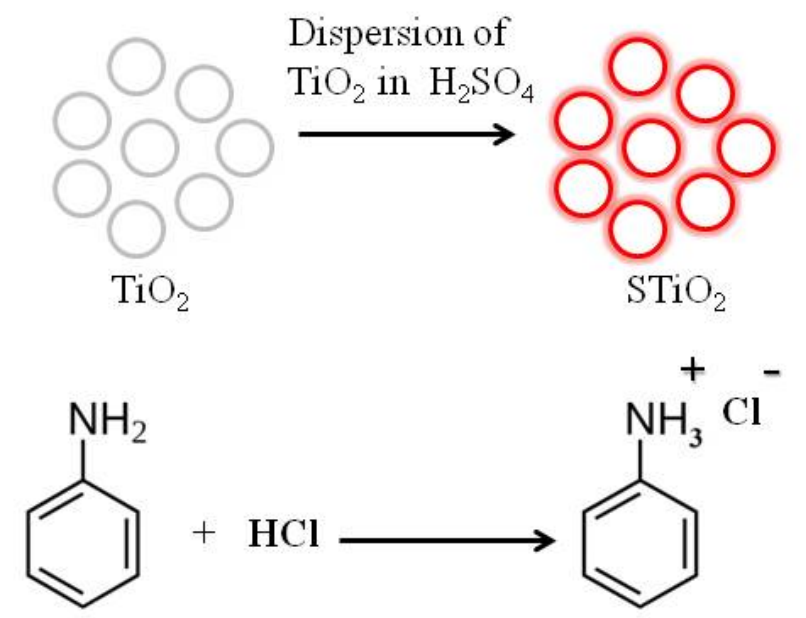

Aniline

Anilinium Chloride

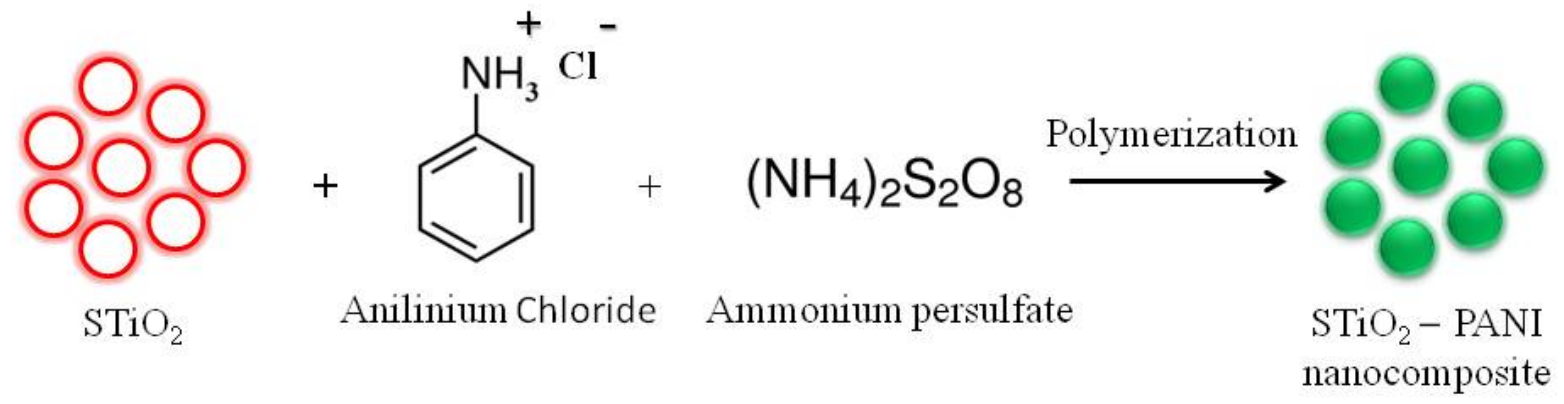

545

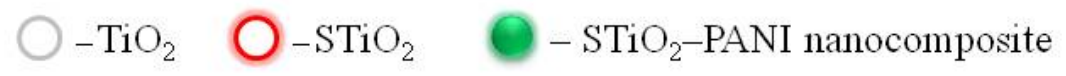

546 Fig. 1. Schematic representation of Polyaniline coated sulfonated $\mathrm{TiO}_{2}$ nanoparticles 


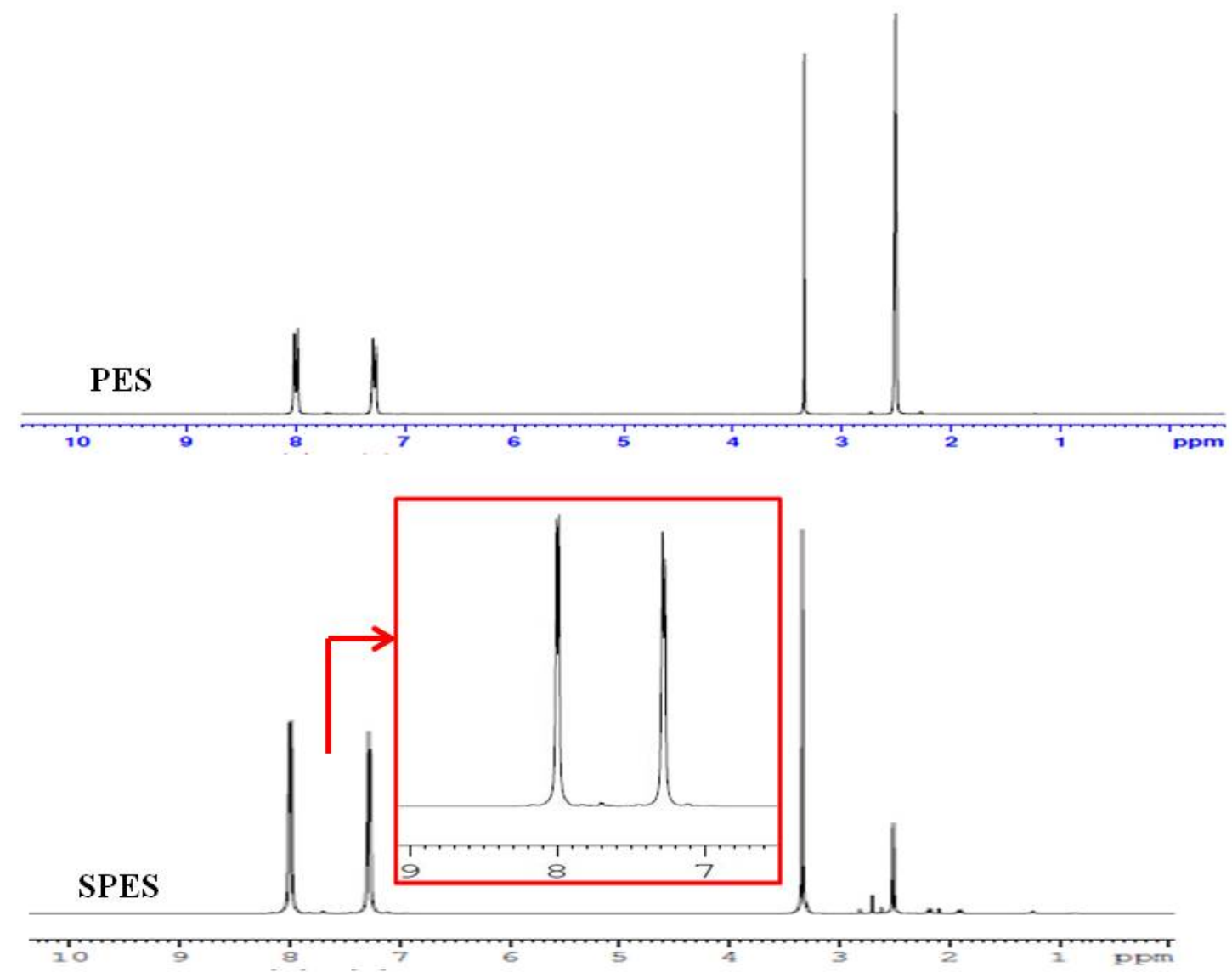

554

555

Fig. 2. ${ }^{1} \mathrm{H}-\mathrm{NMR}$ spectra of PES and SPES.

556 


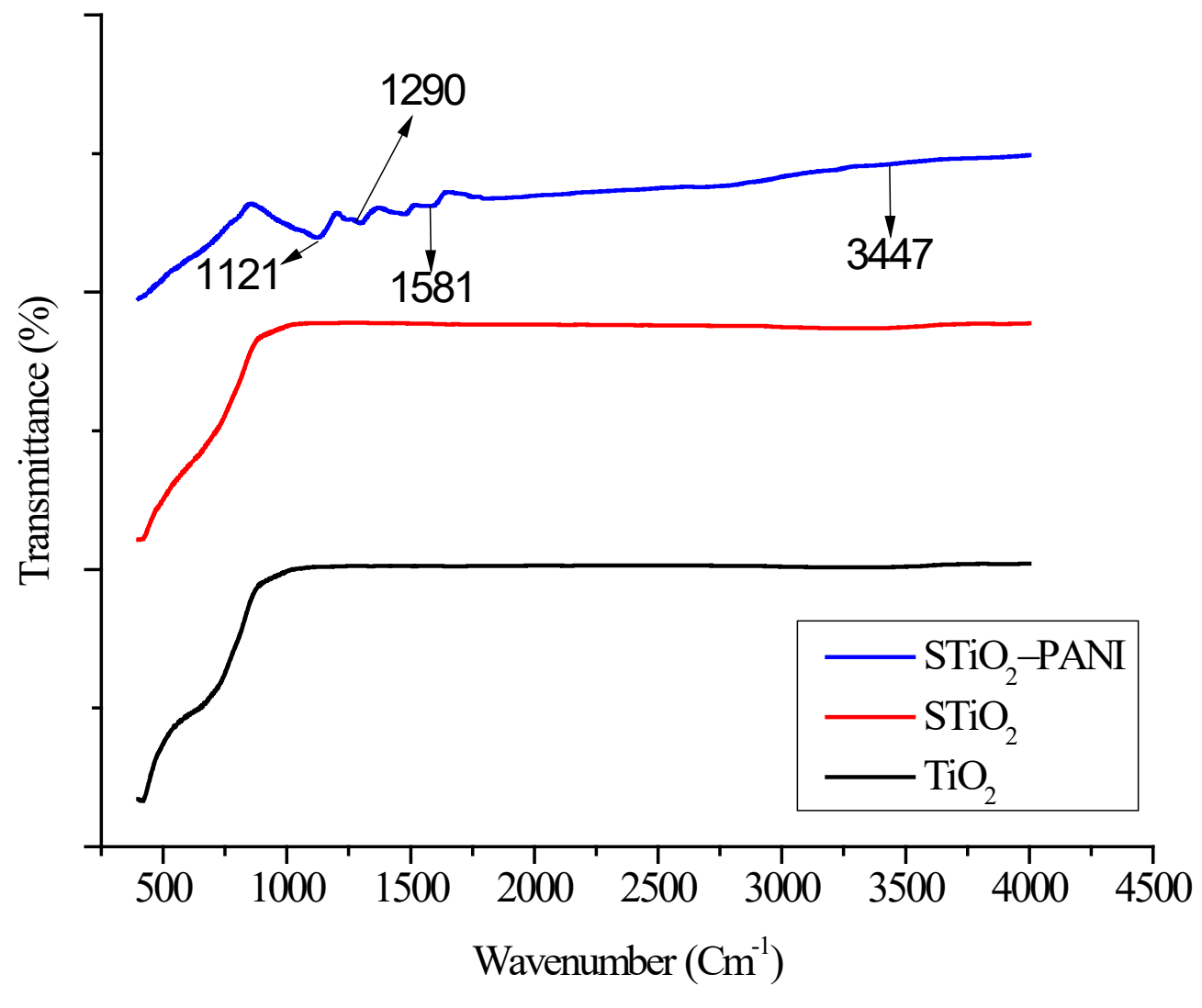

557

558 Fig. 3. FTIR spectra of $\mathrm{TiO}_{2}, \mathrm{STiO}_{2}$ and $\mathrm{STiO}_{2}-\mathrm{PANI}$.

559

560

561

562

563

564 


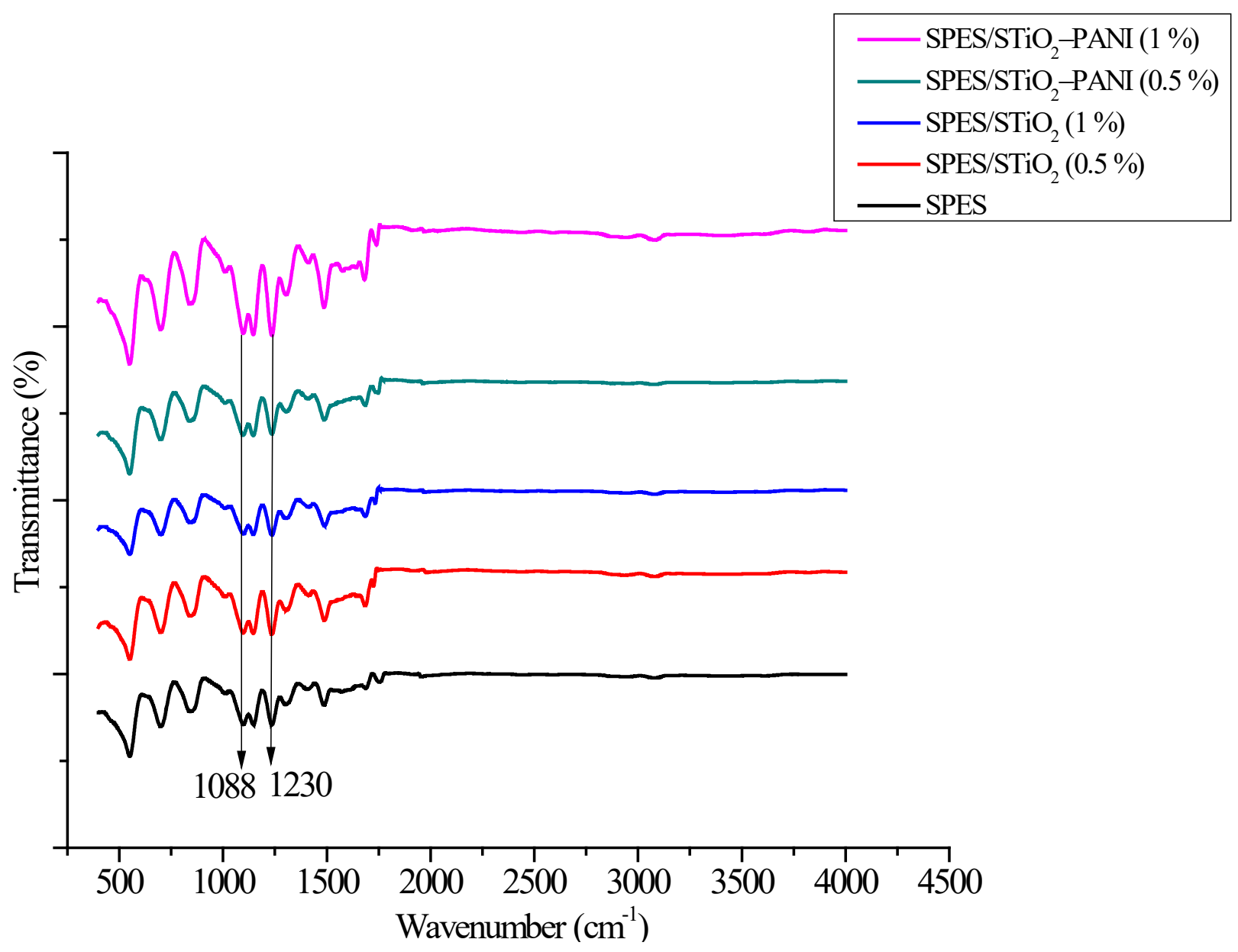

566 Fig. 4. FTIR spectra of pristine SPES and SPES composite membranes.

567

568

569

570

571 


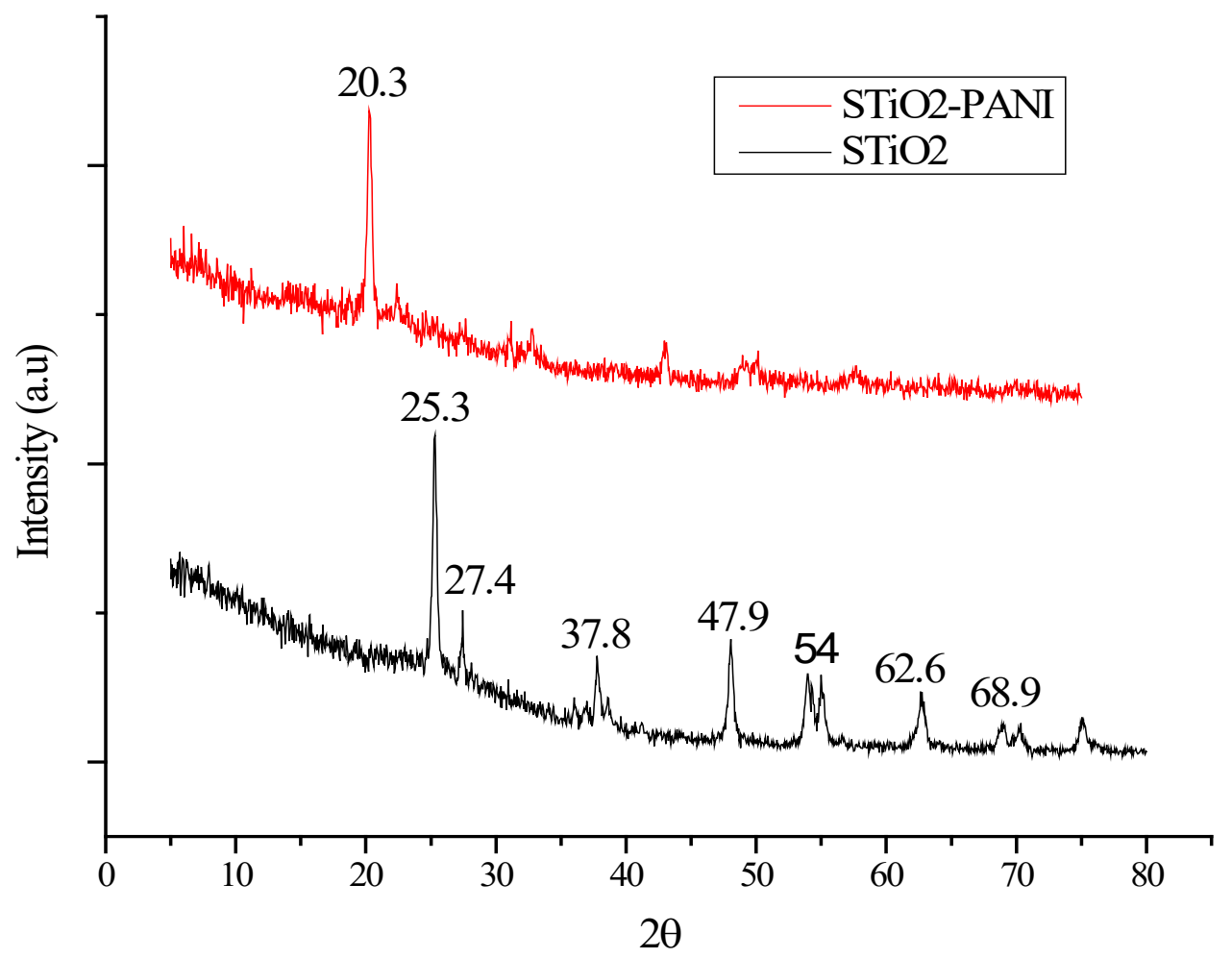

572

573 Fig. 5. XRD pattern of $\mathrm{STiO}_{2}$ and $\mathrm{STiO}_{2}-\mathrm{PANI}$.

574

575

576

577

578 


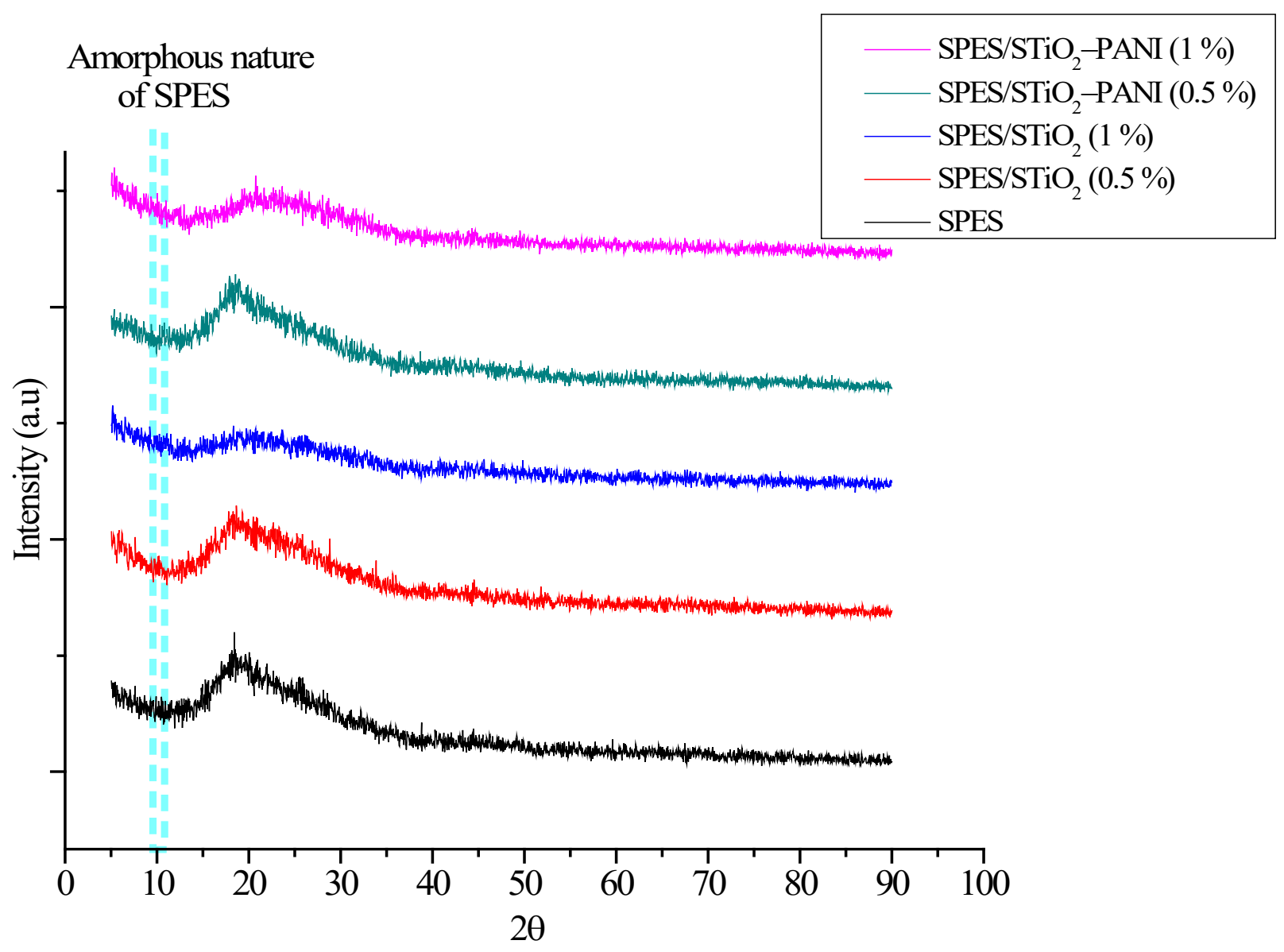

580

Fig. 6. XRD pattern of pristine SPES and SPES composite membranes.

581

582

583

584

585

586

587 

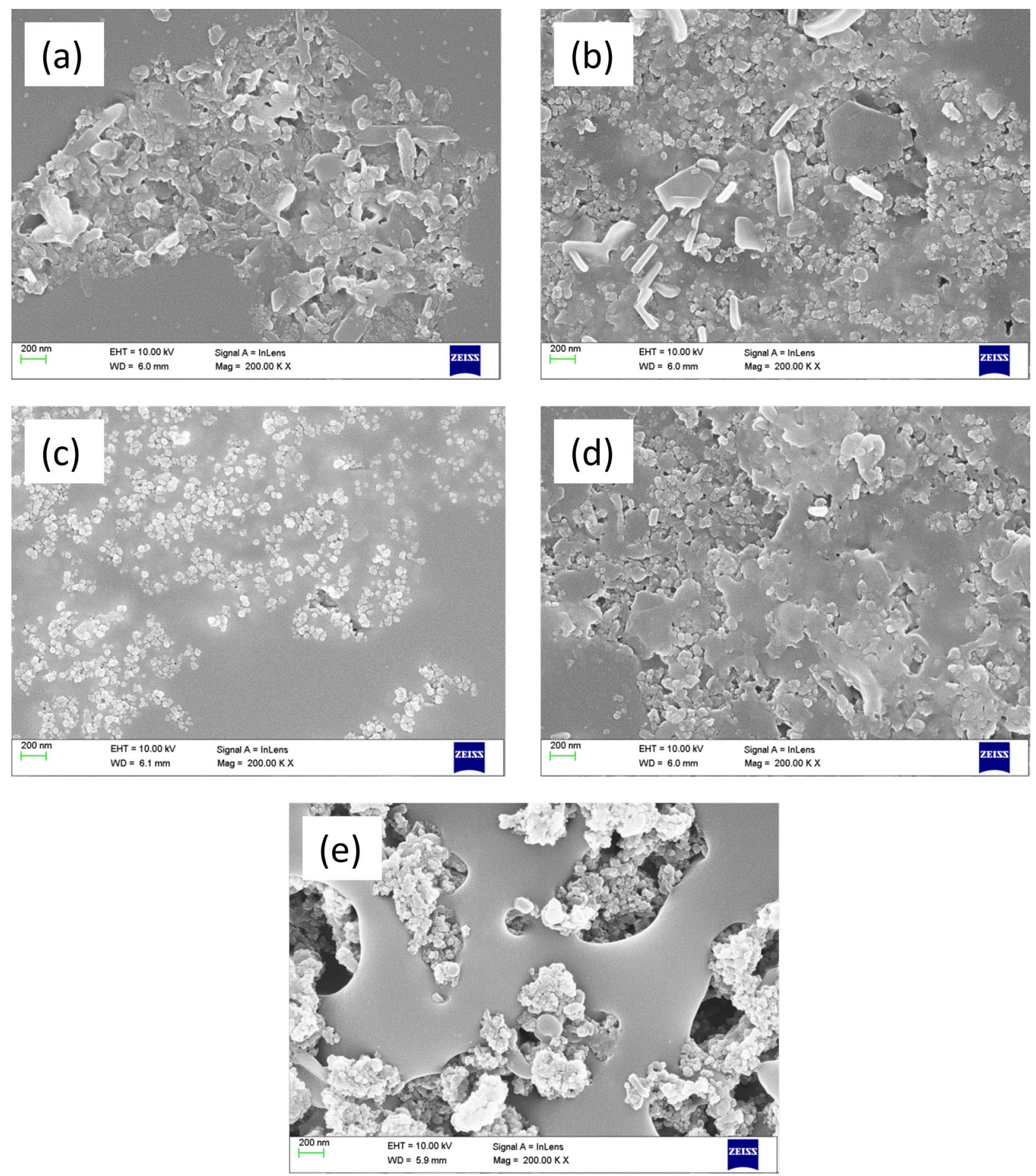

589 Fig. 7. FESEM images of the membranes (a) SPES, (b) SPES/STiO $2(0.5 \%)$, (c) SPES/ $\mathrm{STiO}_{2}$ 590 (1\%), (d) SPES/ STiO $2-P A N I\left(0.5 \%\right.$ ), and (e) SPES/ $\mathrm{STiO}_{2}-\mathrm{PANI}(1 \%)$. 


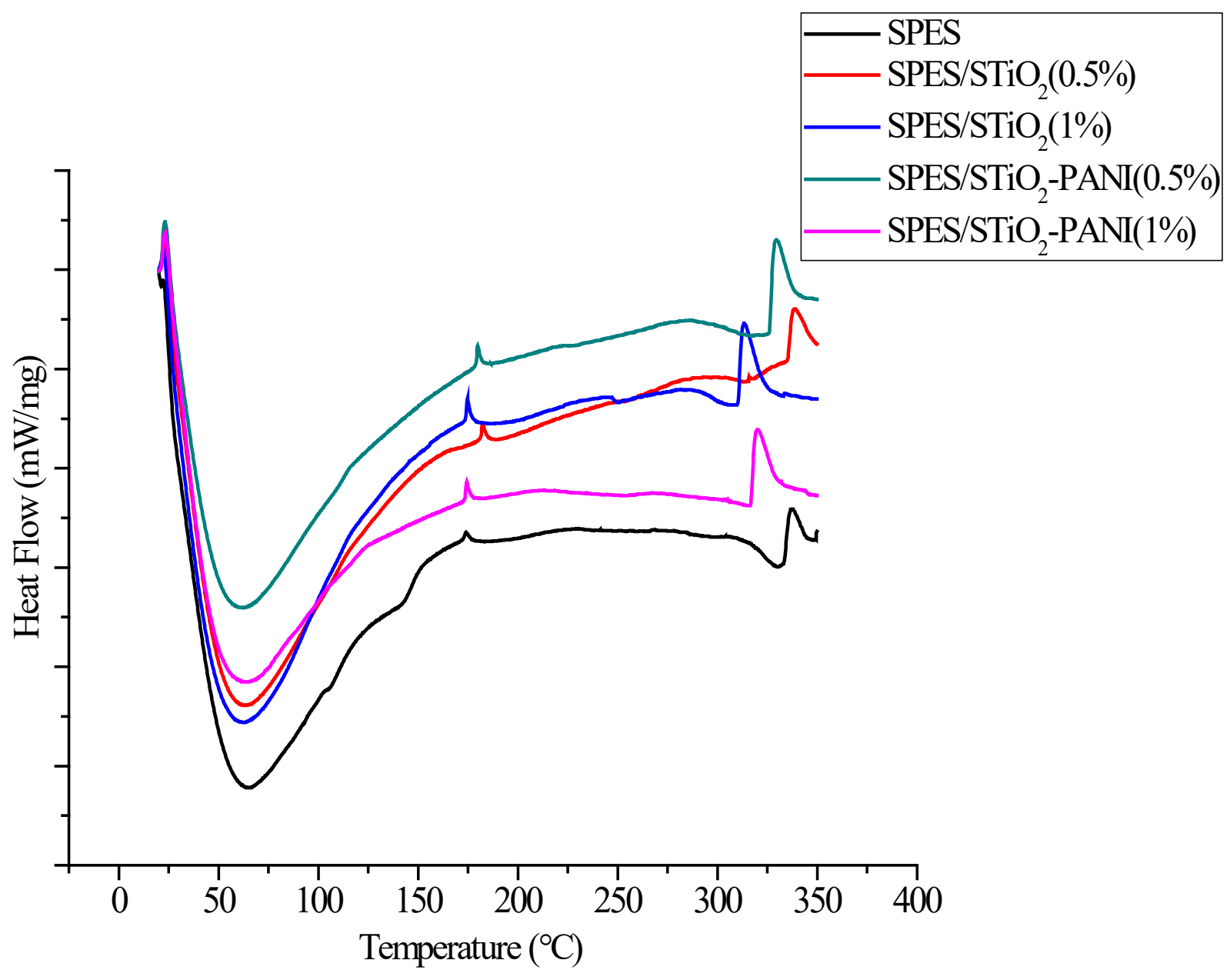

Fig. 8. DSC thermogram of pristine SPES and SPES composite membranes.

594

595 